\title{
SELF-ESTEEM MEDIATES RELATIONSHIPS BETWEEN SELF-CONCEPT CLARITY AND PERCEPTIONS OF THE FUTURE
}

\author{
ADRIAN MORAWIAK \\ SWPS University of Social Sciences and Humanities, \\ Department of Psychology, ul. Chodakowska 19/31, Warszawa, Poland \\ E-mail address: morawiak.adrian@gmail.com

\section{BŁAŻEJ MROZIŃSKI} \\ SWPS University of Social Sciences and Humanities, \\ Department of Psychology, ul. Chodakowska 19/31, Warszawa, Poland \\ E-mail address: bmrozinski@swps.edu.pl

\section{JOANNA GUTRAL} \\ SWPS University of Social Sciences and Humanities, \\ Department of Psychology, ul. Chodakowska 19/31, Warszawa, Poland \\ E-mail address: jgutral@swps.edu.pl

\section{MARZENA CYPRYAŃSKA} \\ SWPS University of Social Sciences and Humanities, \\ Department of Psychology, ul. Chodakowska 19/31, Warszawa, Poland \\ E-mail address: mcypryanska@swps.edu.pl

\section{JOHN B. NEZLEK} \\ jbnezl@wm.edu \\ SWPS University of Social Sciences and Humanities, \\ Department of Psychology, ul. Chodakowska 19/31, Warszawa, Poland; \\ The College of William and Mary, Williamsburg, Virginia, USA \\ E-mail address: jbnezl@wm.edu
}

\begin{abstract}
Aim. The present study was designed to examine relationships between young people's self-concepts and their perceptions of their futures

Methods. High school students $(n=347)$ completed measures of the two domains of self-concept, the evaluative domain, self-esteem, and the knowledge or structural
\end{abstract}


domain, self-concept clarity. They also completed two measures of perceptions of their futures, optimism and future time perspective.

Results. Both measures of self-concept were positively correlated with both measures of perception of the future. For both measures of perceptions of the future, regression analyses found that when perceptions of the future were regressed onto the two measures of self-concept perceptions of the future were significantly related to only self-esteem. Relationships between perceptions of the future and self-concept clarity were not significant. Analyses of mediation revealed that self-esteem mediated the relationship between self-concept clarity and both measures of perceptions of the future.

Conclusion. Young people with a clearer sense of self and who have higher selfesteem are more optimistic and perceive a longer future than young people with a less clear sense of self and who have lower self-esteem; however, the effects of self-concept clarity disappear after the relationship between clarity and self-esteem are taken into account.

Key words: self-esteem, self-concept clarity, future orientation, optimism

\section{INTRODUCTION}

People's perceptions of their futures can serve as important influences on their present behaviours. For example, if people view their futures as hopeless, they may be unmotivated to try to improve their present circumstances or to make plans for a more adaptive future. Such a possibility is the foundation of one of the leading models of depression, the learned helplessness model (Abramson, Seligman, \& Teasdale, 1978). In contrast, if people think of their futures more positively, they are more likely to engage in behaviours that promote both their present and future well-being (e.g., Carver, Scheier, \& Segerstrom, 2010). Moreover, self-concept is a critical component of how people formulate their visions of the future. For example, low self-esteem is associated with greater level of distress, particularly depression (Orth, \& Robins, 2013), and depression is associated with decreased optimism.

Using research on perceptions of the future and research on self-concept as a starting point, the present study examined relationship between self-concept and perceptions of the future among a sample of high-school students. We studied high school students because adolescence can be an important period in life in terms of "setting the stage" for later life. For example, at this time, people may choose to attend university or not, and this decision can have a profound effect on their options in the future. We present the hypotheses and expectations that guided our study proceeded by relevant literature review.

\section{PERCEPTIONS OF THE FUTURE}

The future can be conceptualized in various ways. People can think of a job they might have, of the type of relationships they will have, where they will live, how they think they will feel, and so forth. For present purposes we measured people's perceptions of their futures in terms of two constructs, optimism 
and time perspective. We thought that these two constructs would provide complementary insights into young people's perceptions of their futures.

We relied upon a definition of optimism proposed by Carver, et al. (2010): "Optimism is an individual difference variable that reflects the extent to which people hold generalized favorable expectancies for their future" (p. 879). As a result of their review, Carver et al. concluded that optimism had numerous positive outcomes, including psychological well-being. Although they did not mention self-esteem per se, the correlates of optimism they described are also part of the nomological network of self-esteem. Interestingly, Carver et al. did not specifically address causal relationships between optimism and the other constructs with which they were concerned. They assumed that optimism led to certain outcomes rather than reverse. We address this issue below.

Another way we conceptualized perceptions of the future relied upon the construct of time perspective introduced by Carstensen and colleagues (e.g., Lang, \& Carstensen, 2002). Future time perspective (FTP) refers to the extent to which people see their futures as open or limitless versus limited. Although much of the research on FTP has concerned age differences in FTP (older adults have been found to have more limited FTP than younger adults), some has concerned relationships between self-esteem and FTP. This research suggests that self-esteem is positively related to how open people view their futures to be (e.g., Davis, Hicks, Schlegel, Smith, \& Vess, 2015). Moreover, FTP has been found to be positively related to optimism (e.g., Allemand, Hill, Ghaemmaghami, \& Martin, 2012).

\section{THE EVALUATIVE AND KNOWLEDGE COMPONENTS OF SELF-EVALUATION}

The self is one of the most studied topics in psychology, and the self has been studied using a nearly incomprehensible number of frameworks within the context of an equally large number of theories. Nevertheless, many measures of the self can be understood in terms of the extent to which they concern two broad dimensions (e.g., Nezlek, \& Plesko, 2001) of self-concept. The first, and by far the most commonly studied dimension, is the evaluative dimension, and it refers to how positively people value themselves. Perhaps the prototypical measure of self-evaluation is Rosenberg's (1965) classic measure of self-esteem.

The second dimension reflects what is sometimes referred to as the knowledge component, and one way this knowledge component has been conceptualized is in terms of a construct called self-concept clarity. Self-concept clarity (SCC) refers to the extent to which self-beliefs are internally consistent, stable, and clearly defined (Campbell, 1990; Campbell, at al., 1996). It is important to note that variability in SCC reflects variability in the consistency and confidence of beliefs about the self. It does not reflect the content or accuracy of beliefs about the self. 
The bulk of research on relationships between self-esteem and SCC had found that the two are positively related (e.g., Campbell et al., 1996; Nezlek, \& Plesko, 2001). People who have higher self-esteem, have clearer self-concepts and vice-versa. It is important to note however, that self-concept clarity is distinct from self-esteem. The two constructs covary independently of their covariance with various other measures including the factors of the Five Factor Model of personality and private self-consciousness (Campbell et al., 1996). Moreover, as noted by Campbell et al. (1996) in terms of self-esteem and SCC considered in isolation, there is no reason to assume the causal precedence of one over the other.

\section{THE PRESENT STUDY: RELATIONSHIPS BETWEEN SELF-CONCEPT AND PERCEPTIONS OF THE FUTURE}

Although the self serves as an important basis for thinking about the future, relationships between perceptions of the future and self-concept have not received much attention, at least in terms of the evaluative and knowledge components that we have discussed, and the present study was designed to examine such relationships. We collected measures of the evaluative and knowledge components of self-concept, self-esteem and self-concept clarity respectively, and we collected two measures of perceptions of the future, a measure of future time perspective and a measure of optimism.

The lack of directly relevant theory and research made it difficult to pose detailed hypotheses; nevertheless, there was enough to provide a basis for some general expectations. The general principle underlying our expectations was that an individual's present self-concept provides a basis for making predictions about the future. Overall, we expected that both self-esteem and selfconcept clarity would be positively related to both measures of perceptions of the future. Individuals whose self-esteem was higher would be more optimistic and would see a more open future compared to individuals whose self-esteem was lower. Similarly, we expected that individuals when had a clearer sense of who they were, would be more optimistic and would see a more open future compared to individuals who had a less clear sense of who they were. On a somewhat more speculative basis, we also examined mediational relationships among our measures. Would self-esteem mediate relationships between self-concept clarity and perceptions of the future or vice-versa? In this regard, previous research and theory provided no guidance at all, so we truly had no specific expectations.

Our logic also assumes that self-concept leads to perceptions of the future instead of the opposite causal sequence. This assumption was based on the conclusion drawn from the research review on relationships between selfesteem and depression by Orth and Robins (2013). They concluded: "Overall, the available evidence provides strong support for the vulnerability model (low self-esteem contributes to depression), weaker support for the scar model 
(depression erodes self-esteem)..." (p. 455). Given how important perceptions of the future are in the etiology and maintenance of depression, we assumed that self-esteem would be related to this critical feature of depression in the same way it was related to depression itself.

\section{MATERIAL AND METHODS}

Participants and procedure

Participants were 347 high school students (189 women and 158 men) aged 15 to $17(M=16.55, S D=0.98)$. Participants were asked to volunteer for a study about their life satisfaction. Participants were under 18 years old and so a parent or legal guardian needed to sign a consent form to allow them to participate. Only students who provided such signed consent were allowed to take part in that study. No incentives were offered for participation nor were there any penalties for not participating. Participants were told that their responses would be anonymous and that they had the right to discontinue participation at any time without giving a reason why. The data were collected during a community meeting that each class had with their lead teacher each week. These meetings lasted 45 minutes, and participants completed the questionnaires at that time.

We collected two measures of self-concept. One, the Rosenberg Self-esteem scale (RSE; Rosenberg, 1965), was a measure of the evaluative component of self-concept, and the other, the Self-Concept Clarity scale (SCC; Campbell et al., 1996), was a measure of the knowledge component. We also collected two measures of perceptions of the future. One was the Future Time Perspective Scale (FTP; Lang, \& Carstensen, 2002), the other was the Life Orientation Test (LOT; Scheier, Carver, \& Bridges, 1994). We used Polish language versions of all measures.

Due to the fact that participants were volunteers and the data were collected in classes, we wanted to minimize the total number of items we asked participants to answer. Based on published factor analyses and examination of the items, we reduced the number of items in the RSE, SCC, and LOT. Note that item numbers are taken from the item numbers as presented in the original published English language versions of the scales. For the FTP, we used all ten items from the original scale. For the RSE we used items 1, 6, 7, 8, 9, and 10. For the SCC we used items 1, 3, 4, 8, 11, and 12. For the LOT, we used items 3, 4, 7 and 10.

For the FTP, we used a 1-7 scale with endpoints labelled "definitely not true" and "definitely true." For the LOT, we used a 0-4 scale with endpoints labelled "definitely does not refer to me" and "definitely refers to me." For the RSE, we used a 1-4 scale with endpoints labelled "I strongly agree" and "I strongly disagree." For the SCC, we used a 1-5 scale with endpoints labelled "I definitely disagree" and "I definitely agree." The raw data for this study and copies of the scales that we used are available on the Open Science Framework repository. 


\section{RESULTS}

Before conducting the primary analyses we inspected participant's responses to ensure that they had answered thoughtfully. We defined a careless responder as someone who provided identical answers to all the items for a measure even when the items would logically require different responses, e.g., positively and negatively valenced items (Meade, \& Craig, 2012). Participants who did this on one or more measures were excluded from the analyses, leaving a final sample of 334 .

To provide a context for understanding the analyses that examined the relationships among our measures, univariate summary statistics for the measures are presented in Table 1. Before estimating the reliabilities we scored all items so that a higher score represented more of the construct being measured, higher self-esteem, more optimism, and so forth. The resulting reliabilities indicated that our scales had at least "fair" reliability according to Shrout (1998). Also, as can be seen from the data in Table 1, the mean scores were in the middle of their respective scales suggesting that floor and ceiling effects were not an issue.

As expected, the measures we collected were positively correlated, relationships that are consistent with what has been found in the past. These correlations indicated that young people who had a clearer sense who they are, saw their futures more optimistically and as having a longer time perspective than young people with a less clear sense of who they are. Similarly, young people with higher self-esteem saw their futures more optimistically and as having a longer time perspective than young people with lower self-esteem.

Table 1. Descriptive statistics and correlations between measures

\begin{tabular}{ccccccc} 
& M & SD & alpha & LOT & RSE & SCC \\
\hline FTP & 4.72 & .81 & .75 & .36 & .44 & .24 \\
LOT & 2.44 & .74 & .64 & & .50 & .21 \\
RSE & 2.77 & .58 & .81 & & & .54 \\
SCC & 2.73 & .81 & .76 & & & \\
\hline
\end{tabular}

Given the positive correlation between self-esteem and self-concept clarity, we needed to determine if relationships between perceptions of the future and these two measures were independent. First, we conducted two multiple regressions, one in which FTP scores were the outcome and scores on our measures of self-concept (RSE and SCC) were predictors, and the other in which scores on the LOT were the outcome and scores on the RSE and SCC were predictors. When FTP scores were regressed onto RSE and SCC scores, the test of the of the overall model was significant, $F(2,331)=39.80, p<.001, R^{2}=.19$; however, the coefficient for the SCC was not significant $(\beta=.01, t<1)$, whereas the coefficient for RSE was significant $(\beta=.44, t(331)=7.53, p<.001)$. Recall that the zero-order correlation between the FTP and the SCC was significant $(r=.24, p<.001)$. This pattern suggests that self-esteem mediated relationships between self-concept clarity and 
future time perspective. The same pattern occurred when LOT was regressed on RSE and SCC. When LOT scores were regressed onto RSE and SCC scores, the test of the of the overall model was significant, $F(2,331)=54.68, p<.001, R^{2}=$ .25 ; however, the coefficient for SCC was not significant $(\beta=-.07, t<1)$, whereas the coefficient for RSE was significant $(\beta=.53, t(331)=9.44, p<.001)$. Recall that the zero-order correlation between LOT and SCC scores was significant $(r=.21$, $p<.001)$. This pattern suggests that self-esteem mediated relationships between self-concept clarity and optimism.

To examine the possibility that self-esteem mediated relationships between self-concept clarity and our measures of perception of the future, we conducted analyses using the PROCESS (v. 2.16.3) macro for SPSS, a set of procedures developed by Hayes (2013) to examine mediation within multiple regression. We used variants of Model 4 of this procedure with 10,000 bootstrapped samples and $95 \%$ confidence intervals. In one analysis the outcome variable was FTP, the mediator was RSE, and the independent variable was SCC. In a second analysis, the outcome variable was LOT, the mediator was RSE, and the independent variable was SCC.

The results of these analyses were quite clear and are illustrated in Figure 1. Self-esteem mediated the relationship between future time perspective and self-concept clarity. The direct effect of self-concept clarity on future time perspective was not significant, -.001 ( $s e=.059, t=<1$, CI: -.114 to .116 ), whereas the indirect effect of self-esteem on future time perspective was significant, .236 $(s e=.041, z=6.29, p<.001, \mathrm{CI}$ : .163 to .327). Similarly, self-esteem mediated the relationship between optimism and self-concept clarity. The direct effect of self-concept clarity on optimism was not significant, -.065 ( $s e=.052, t=1.25$, CI: -.166 to .036), whereas the indirect effect of self-esteem on optimism was significant, .261 ( $s e=.034, z=7.29, p<.001, \mathrm{CI}$. .199 to .336 ).

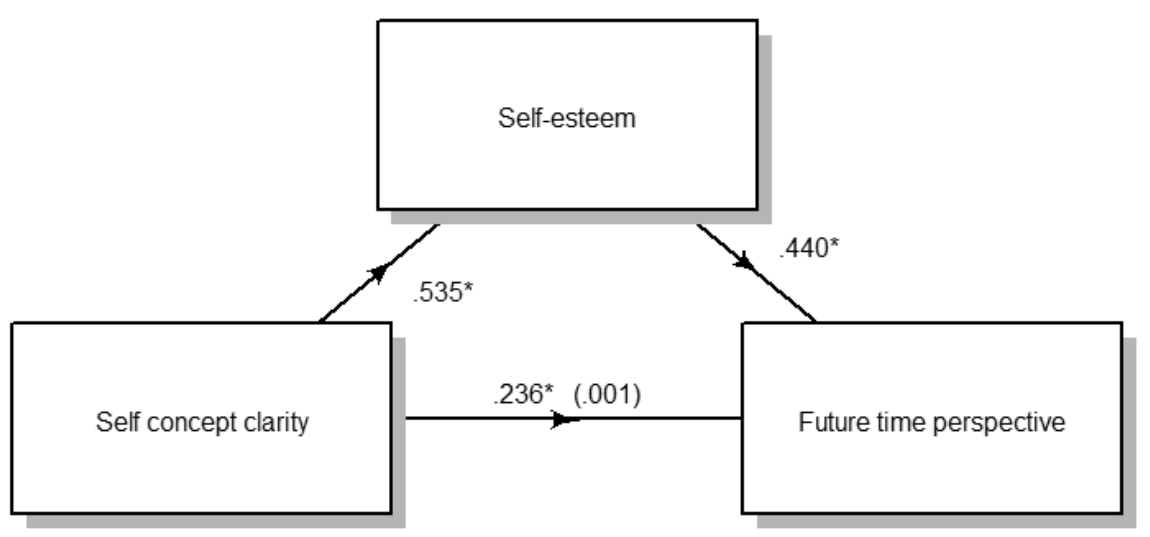

Figure 1. Standardized regression coefficients for the relationship between self-concept clarity and future time perspective as mediated by self-esteem.

Note: The standardized regression coefficient between self-concept clarity and future time perspective, controlling for self-esteem, is in parentheses. ${ }^{*} p<.001$ 


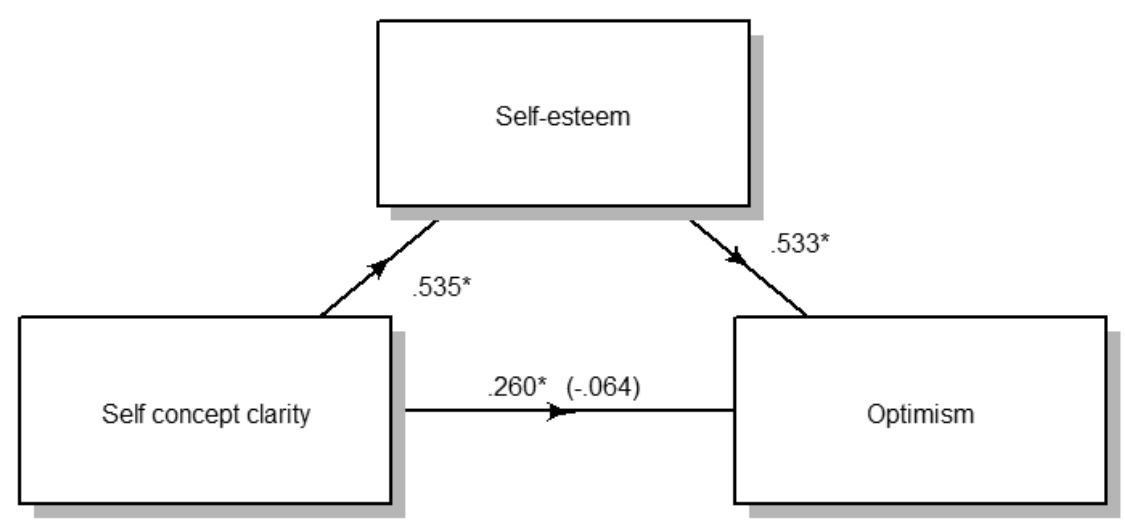

Figure 2. Standardized regression coefficients for the relationship between self-concept clarity and optimism as mediated by self-esteem

Note: The standardized regression coefficient between self-concept clarity and optimism, controlling for self-esteem, is in parentheses. ${ }^{*} p<.001$

\section{DISCUSSION}

As expected, we found that self-concept was positively related to perceptions of the future. Both self-esteem and self-concept clarity were positively related to optimism and to the length of people's future time perspective. Moreover, we found that self-esteem mediated relationships between selfconcept clarity and people's perceptions of their futures. The mediational relationships we found, suggest that relationships between self-concept clarity and perceptions of the future occurred because of the relationships between self-esteem and self-concept clarity, and that self-concept clarity is not directly related to perceptions of the future. Therefore, we will limit our discussion to relationships between self-esteem and perceptions of the future.

When people think of their futures they use the present as part of this construction in part because the present consists of immediately available stimuli and information. Moreover, the self is the mechanism that processes experience making the self one of the most important aspects of the present. Granting this, self-evaluation is an important part of the basis people use to make judgments about the future.

For example, we used the following item to measure self-esteem: "On the whole, I am satisfied with myself," and we measured optimism with this item: "Overall, I expect more good things to happen to me than bad." It would be inconsistent (dissonant) for someone to endorse the first item strongly while endorsing the second item weakly. Being satisfied with one's self includes (at least to some extent) being satisfied with one's life (e.g., Pavot, \& Diener, 2008), and so how people evaluate themselves in the present (self-esteem) should be related to how they suppose their lives will be in the future. 
Relationships between self-esteem and future time perspective may also reflect the variance they share with a third construct: self-efficacy. As noted by Bandura (1997), self-esteem is positively related to self-efficacy, and some of the items on the future time perspective scale we used seem to be similar to how self-efficacy is measured. For example, one item from the future time perspective scale is "I could do anything I want in the future," one item from a popular measure of self-efficacy (Schwarzer \& Jerusalem, 1995) is "It is easy for me to stick to my aims and accomplish my goals." Believing that one can accomplish things in the present would predispose one to believe that he or she could accomplish things in the present.

\section{LIMITATIONS AND FUTURE DIRECTIONS}

The present study clearly has its limitations. First, our results describe a sample of younger people from a specific place. Although there is no reason to believe that Polish students differ from students of a similar age who live in other, industrialized and economically developed countries, they might. More likely is the possibility that relationships between the self and perceptions of the future differ from the present results among people who live in cultures in which the self is defined differently for example in terms of self-construal (Cross, Hardin, \& Gercek Swing, 2011). Determining if such differences exist requires studying individuals from such cultures or measuring individual differences in self-construal.

Second, there is the limitation inherent in our use of a sample of young people. A considerable body of research has found that the future time perspective of older people is shorter than the future time perspective of younger people (e.g., Lang, \& Carstensen, 2002). This research has also found that for older people this shortened time perspective is associated with increased positive affect and well-being because older people focus on the more positive aspects of their lives. This suggests that relationships between future time perspective and self-concept among older people may differ from the relationships between these measures we found in our sample of younger people. In contrast, no age differences have been proposed for relationships between optimism and other constructs. Examining such possibilities will require studying a sample of older people and comparing the results to those from a sample of younger people. There is also the issue of the specific measures we used. Although we used well-validated and widely used measures of both self-concept and perceptions of the future, it is possible that different measures would have led to different results.

Despite the limitations of the present study we believe the results contribute to our understanding of how young people perceive their futures. Although having a clear sense of self may be associated with more positive perceptions of the future, upon closer inspection, such relationships are probably due to the fact that people who have a clearer sense of self have higher self-esteem. We 
hope that the present study has provided some useful insights into the factors that influence how people construct their futures as well as the types of methods and statistical analyses that can be used to study such topics.

\section{REFERENCES}

1. Abramson, L. Y., Seligman, M. E. P., \& Teasdale, J. D. (1978). Learned helplessness in humans: Critique and reformulation. Journal of Abnormal Psychology, 87(1), 49-74. doi:10.1037/0021-843X.87.1.49.

2. Allemand, M., Hill, P. L., Ghaemmaghami, P., \& Martin, M. (2012). Forgivingness and subjective well-being in adulthood: The moderating role of future time perspective. Journal of Research in Personality, 46, 32-39. doi:10.1016/j.jp. 2011.11.004

3. Bandura, A. (1997). Self-efficacy: The exercise of control. New York: W.H. Freeman.

4. Campbell, J. D. (1990). Self-esteem and the clarity of the self-concept. Journal of Personality and Social Psychology, 59, 538-549. doi:10.1037/0022-3514.59.3.538

5. Campbell, J. D., Trapnell, P. D., Heine, S. J., Katz, I. M., Lavallee, L. F., \& Lehman, D. R. (1996). Self-concept clarity: Measurement, personality correlates, and cultural boundaries. Journal of Personality and Social Psychology, 70, 141-156. doi:10.1037/0022-3514.70.1.141

6. Carver, C. S., Scheier, M. F., \& Segerstrom, S. C. (2010). Optimism. Clinical Psychology Review, 30, 879-889. doi:10.1016/j.cpr.2010.01.006

7. Cross, S. E., Hardin, E. E., \& Gercek Swing, B. (2011). The what, how, why, and where of selfconstrual. Personality and Social Psychology Review, 15, 142-179. doi:10.1177/1088868310373752

8. Davis, W. E., Hicks, J. A., Schlegel, R. J., Smith, C. M., \& Vess, M. (2015). Authenticity and self-esteem across temporal horizons. The Journal of Positive Psychology, 10(2), 116-126. doi:10. 1080/17439760.2014.910830

9. Hayes, A. F. (2013). Introduction to mediation, moderation, and conditional process analysis: A regression-based approach. New York: The Guilford Press.

10. Lang, F. R., \& Carstensen, L. L. (2002). Time counts: Future time perspective, goals, and social relationships. Psychology and Aging, 17, 125-139. doi:10.1037//0882-7974.17.1.125

11. Meade, A. W., \& Craig, S. B. (2012). Identifying careless responses in survey data. Psychological Methods, 17(3), 437-455. doi:10.1037/a0028085

12. Nezlek, J. B., \& Plesko, R. M. (2001). Day-to-day relationships among self-concept clarity, self-esteem, daily events, and mood. Personality and Social Psychology Bulletin, 27, 201-211. doi:10.1177/0146167201272006

13. Orth, U., \& Robins, R. W. (2013). Understanding the link between low self-esteem and depression. Current Directions in Psychological Science, 22(6), 455-460. doi:10.1177/0963721413492763

14. Pavot, W., \& Diener, E. (2008). The satisfaction with life scale and the emerging construct of life satisfaction. The Journal of Positive Psychology, 3, 137-152. doi:10.1080/17439760701756946

15. Rosenberg, M. (1965). Society and the adolescent self-image. Princeton, NJ: Princeton.

16. Scheier, M. F., Carver, C. S., \& Bridges, M. W. (1994). Distinguishing optimism from neuroticism (and trait anxiety, self-mastery, and self-esteem): A reevaluation of the Life Orientation Test. Journal of Personality and Social Psychology, 67, 1063-1078. doi:10.1037/0022-3514.67.6.1063

17. Shrout, P. E. (1998). Measurement reliability and agreement in psychiatry. Statistical Methods in Medical Research, 7, 301-317. doi:10.1191/096228098672090967. 